University of Nebraska - Lincoln

DigitalCommons@University of Nebraska - Lincoln

2010

Test method variability in slow crack growth properties of sealing glasses

J. Salem

NASA Glenn Research Center, jonathan.a.salem@nasa.gov

R. Tandon

Sandia National Laboratories

Follow this and additional works at: https://digitalcommons.unl.edu/nasapub

Part of the Physical Sciences and Mathematics Commons

Salem, J. and Tandon, R., "Test method variability in slow crack growth properties of sealing glasses" (2010). NASA Publications. 86.

https://digitalcommons.unl.edu/nasapub/86

This Article is brought to you for free and open access by the National Aeronautics and Space Administration at DigitalCommons@University of Nebraska - Lincoln. It has been accepted for inclusion in NASA Publications by an authorized administrator of DigitalCommons@University of Nebraska - Lincoln. 


\title{
Test method variability in slow crack growth properties of sealing glasses
}

\author{
J. Salem ${ }^{\mathrm{a}, *}$, R. Tandon ${ }^{\mathrm{b}}$ \\ a NASA Glenn Research Center, Cleveland, OH, USA \\ ${ }^{\mathrm{b}}$ Sandia National Laboratories, Albuquerque, NM, USA
}

\section{A R T I C L E I N F O}

\section{Article history:}

Received 3 November 2008

Received in revised form 17 July 2009

Accepted 22 July 2009

Available online 29 July 2009

\section{Keywords:}

Glass

Ceramics

Crack growth

Fracture toughness

Connectors

\begin{abstract}
A B S T R A C T
The crack growth properties of several sealing glasses were measured by using constant stress rate testing in $\sim 2 \%$ and $95 \% \mathrm{RH}$ (relative humidity). Crack growth parameters measured in high humidity are systematically smaller ( $n$ and $B$ ) than those measured in low humidity, and crack velocities for dry environments are $\sim 100 \times$ lower than for wet environments. The crack velocity is very sensitivity to small changes in RH at low RH. Biaxial and uniaxial stress states produced similar parameters. Confidence intervals on crack growth parameters that were estimated from propagation of errors solutions were comparable to those from Monte Carlo simulation. Use of scratch-like and indentation flaws produced similar crack growth parameters when residual stresses were considered.
\end{abstract}

Published by Elsevier Ltd.

\section{Introduction}

Sealing glasses are used in components such as electrical feed through connectors. The glass seals and electrically insulates the connector, and thus fracture of the brittle seal is a concern. In applications such as the space shuttle environmental cut off (ECO) system, the connector seals are subjected to differential pressures at cryogenic temperatures and seal failure can create leakage of dangerous liquids and/or gasses. Failure can occur even under constant load conditions due to stress corrosion cracking in water vapor.

The slow crack growth parameters of several sealing glasses were measured to compare glasses and to help perform life prediction and reliability analysis of components such as feed through connectors. Strength based measurements, which are convenient, were used to generate the data. However, because the statistical scatter in parameters derived from strength data can be very large, the statistical significance of the estimates was checked by estimation of confidence intervals on the parameters via propagation of errors (POE) and Monte Carlo methods. The large scatter is a result of strength not being a material property for glasses, but a function of the fracture toughness and worst flaw present from a variety of sources. Ideally, parameter estimation and design of brittle materials should be done on a fracture mechanics basis (e.g. NASGRO

\footnotetext{
* Corresponding author. Tel.: +1 2164333313.

E-mail address: jonathan.a.salem@nasa.gov (J. Salem).
}

[1]) rather than a strength basis because strength is a function of the highly variable flaw size and relatively consistent fracture toughness.

Although fracture mechanics specimens with large cracks, such as the double-torsion specimen, can be used to measure crack growth with less scatter, the results are complicated by R-curve effects in coarse grain materials such as $\mathrm{ZnSe}$ [2] and diffusion rate effects when the crack size is large relative to that in real components. Strength based testing can be made more akin to fracture mechanics methods by placing a small precrack, such as an indentation, in specimens and thereby reduce scatter, yet test cracks on the order of those encountered in applications. This work investigates and compares the use of natural flaws and small precracks in strength specimens for the generation of crack growth parameters of glasses. Comparison of parameters from strength methods to those from macro-crack fracture mechanics methods is left to future study.

In order to cover the range of environments to which components with sealing glasses are exposed, $\mathrm{RH}$ (relative humidity) of $\sim 2 \%$ and $95 \%$ were considered. To expedite the work, constant stress rate testing of flexure specimens was used. The data was analyzed by linear regression of (1) the individual data points, (2) the median values, and (3) the average values.

In order to investigate the effect of crack type and stress state on parameter variance, an additional set of tests was conducted on a barium-strontium-doped glass by subjecting abraded and dented test specimens to uniaxial and biaxial loading. These flaw 
types and stress states represent the flaws and loads that lead to failure in real components, and could be produced when a hard tool impacts the surface directly or at a shallow angle.

\section{Materials}

The sealing glasses tested ${ }^{1}$ were Corning 0120, Electro-Glass 2164, Schott 8330 borosilicate glass, and Schott S8070 SB glassceramic. In addition, the fracture toughness of several other glasses was measured for comparison: soda-lime silicate, S8061 sealing glass, and the barium-strontium (Ba-doped) glass. With the exception of the as-molded 2164 glass, the test specimens were prepared by diamond grinding in conformance with ASTM C1161 [3]. For the 2164 glass specimens for crack growth testing, the tensile surface was preserved in the as-molded condition.

\section{Experimental procedure}

The elastic modulus of 0120, 2164 and S8061 were determined at $20^{\circ} \mathrm{C}$ by impulse excitation of vibration in accordance with ASTM C 1259 [4]. The mean and standard deviation of 0120 and S8061 were $73.3 \pm 1.6$ and $65.9 \pm 0.1$, respectively. The elastic modulus of 2164 in the as-molded and ground conditions was $62.0 \pm 1.2$ and $63.8 \pm 0.5 \mathrm{GPa}$, respectively.

Fracture strength as a function of stress rate was measured at $20^{\circ} \mathrm{C}$ by using four point flexure of ASTM C1161 [3] size $B$ specimens $(3 \times 4 \mathrm{~mm}$ cross section loaded between 20 and $40 \mathrm{~mm}$ spans) at rates ranging from 0.001 to $1000 \mathrm{MPa} / \mathrm{s}$ in relative humidity ranging from $\sim 2 \%$ to $95 \%$. Humidity was controlled by testing in an enclosure connected to dry and moist air sources that were activated as needed by an electronic controller. Typically, six stress rates were applied with at least five specimens per rate. For the purposes of parameter analysis, the inert strength (i.e. the strength in the absence of a corrosive environment) was determined by testing at low $\mathrm{RH}(<2 \%)$ with a stress rate greater than or equal to $1000 \mathrm{MPa} / \mathrm{s}$. This resulted in failure in a fraction of a second. To compare small, uniform precracks and cracks from nat- ural abrasions, Ba-doped glass specimens were subjected to a $10 \mathrm{~N}$ Vickers indentation load or abrasion via 150 grit abrasive paper.

Fracture toughness was measured by using chevron-notch flexure specimens [5] in laboratory ambient ( 30\% RH) air or dry nitrogen. Test specimen stability was monitored via a strain gage placed on the compressive face of the specimen [6].

\section{Data analysis}

The power law formulation:

$v=\frac{d a}{d t}=A K_{I}^{n}=A^{*}\left[\frac{K_{I}}{K_{I C}}\right]^{n}$

was applied in the data analysis, where $v, a$, and $t$ are crack velocity, crack size, and time, respectively. Constants $A$ and $n$ are the material/environment dependent SCG (slow crack growth) parameters, and $K_{I}$ and $K_{I C}$ are, respectively, the Mode $I$ stress intensity factor and the critical stress intensity factor or fracture toughness of the material. For constant stress rate testing based on the power law formulation, the fracture strength, $\sigma_{f}$, is expressed as a function of stress rate as [7]

$\sigma_{f}=\left[B(n+1) \sigma_{i}^{n-2} \dot{\sigma}\right]^{1 / n+1}$

where $\sigma$ is the applied stress rate, $\sigma_{i}$ is the inert strength, and $B$ is a parameter associated with $A, n$, fracture toughness, crack geometry and loading configuration (see Eq. (13)). The SCG parameter $n$ can be determined from a plot of $\log \sigma_{f}$ as a function of $\log \dot{\sigma}$ with Eq. (2) written as

$\log \sigma_{f}=\frac{1}{n+1} \log \dot{\sigma}+\log D$

where

$\log D=\frac{1}{n+1} \log \left[B(n+1) \sigma_{i}^{n-2}\right]$

Once the slope $\alpha$ and intercept $\beta$ are estimated by linear regression of Eq. (3), the parameters $n, D, B$ and $A$, and their standard deviations, $S D_{n}$, etc., are estimated from [8]

$$
\begin{aligned}
& n=\frac{1}{\alpha}-1 \\
& S D_{n} \approx \frac{S D_{\alpha}}{\alpha^{2}} \\
& D=10^{\beta} \\
& S D_{D} \approx 2.3026\left(S D_{\beta}\right)\left(10^{\beta}\right) \\
& B=\frac{\alpha\left(10^{\beta / \alpha}\right)}{\sigma_{i}^{\left(\frac{1}{\alpha}-3\right)}} \\
& S D_{\ln B} \approx \frac{1}{\alpha} \sqrt{Q^{2} \frac{S D_{\alpha}^{2}}{\alpha^{2}}+(\ln 10)^{2} S D_{\hat{\beta}}^{2}+(1-3 \alpha)^{2} S D_{\ln \sigma_{i}}^{2}+2 Q \ln 10 \frac{\operatorname{Cov}(\alpha, \beta)}{\alpha}} \\
& A^{*}=\frac{2 K_{I c}^{2} \sigma_{i}^{\left(\frac{1}{\alpha}-3\right)}}{10^{\beta / \alpha}(1-3 \alpha) Y^{2}}=\frac{2 K_{I c}^{2}}{B(n-2) Y^{2}} \\
& S D_{\text {lnA }} \approx \frac{1}{\alpha} \sqrt{4 \alpha^{2} \frac{S D_{K_{I C}}^{2}}{K_{I C}^{2}}+\left(Q-\frac{\alpha}{1-3 \alpha}\right)^{2} \frac{S D_{\alpha}^{2}}{\alpha^{2}}+(\ln 10)^{2} S D_{\beta}^{2}+(1-3 \alpha)^{2} S D_{\ln \sigma_{i}}^{2}+2 \ln 10\left(Q-\frac{\alpha}{1-3 \alpha}\right) \frac{\operatorname{Cov}(\alpha, \beta)}{\alpha}} \\
& A=\frac{2 K_{I c}^{\left(3-\frac{1}{\alpha}\right)} \sigma_{i}^{\left(\frac{1}{\alpha}-3\right)}}{10^{\beta / \alpha}(1-3 \alpha) Y^{2}}=\frac{2 K_{I c}^{2-n}}{B(n-2) Y^{2}} \\
& S D_{\ln A} \approx \frac{1}{\alpha} \sqrt{(3 \alpha-1)^{2} \frac{S D_{K_{I c}}^{2}}{K_{I c}^{2}}+\left(Q-\frac{\alpha}{1-3 \alpha}-\ln K_{I c}\right)^{2} \frac{S D_{\alpha}^{2}}{\alpha^{2}}+(\ln 10)^{2} S D_{\beta}^{2}+(1-3 \alpha)^{2} S D_{\ln \sigma_{i}}^{2}+2 \ln 10\left(Q-\frac{\alpha}{1-3 \alpha}-\ln K_{I c}\right) \frac{\operatorname{Cov}(\alpha, \beta)}{\alpha}}
\end{aligned}
$$

\footnotetext{
${ }^{1}$ Certain commercial materials are identified in order to adequately specify the experimental procedure and results. Such identification does not imply any endorsement.
} 
where $Q=\alpha-\beta \ln 10+\ln \sigma_{i}$

and $\operatorname{Cov}(\alpha, \beta)=-S D_{\alpha}^{2}(\overline{\log \dot{\sigma}})$

where $\overline{\log \dot{\sigma}}$ is the mean of the logs of the applied stressing rates, $Y$ is the geometry correction factor for the stress intensity factor, and the standard deviation associated with the inert strength $\left(S D_{l n \sigma i}\right)$ is calculated in logarithmic space. Probability limits on the parameters $B$ and $A$ can be calculated from:

$\underset{\text { Lower }}{B_{\text {Upper }}}=\operatorname{EXP}\left[\ln B \pm t\left(S D_{\ln B}\right)\right] \quad$ and $A_{\text {Upper }}=E X P\left[\ln A \pm t\left(S D_{\ln A}\right)\right]$

by using Student's $t$ distribution for the DOF and probability level desired. If the DOF (degrees-of-freedom) is greater than $\sim 40$, then

$$
\underset{\text { Lower }}{B_{\text {Upper }}}=\operatorname{EXP}\left[\ln B \pm \ell\left(S D_{\ln B}\right)\right] \text { and } A_{\text {Lower }}=\operatorname{EXP}\left[\ln A \pm \ell\left(S D_{\ln A}\right)\right]
$$

where $l$ is the number of standard deviations corresponding to the probability level desired. The DOF, $\varphi$, is given by

$$
\begin{aligned}
\frac{\left(S D_{\ln B}^{2}\right)^{2}}{\varphi_{\ln B}}= & \frac{1}{\phi_{\ln \sigma_{i}}}\left[\frac{(1-3 \alpha)^{2}}{\alpha^{2}} S D_{\ln \sigma_{i}}^{2}\right]^{2} \\
& +\frac{1}{\phi_{\alpha \beta}}\left[Q^{2} \frac{S D_{\alpha}^{2}}{\alpha^{4}}+(\ln 10)^{2} \frac{S D_{\beta}^{2}}{\alpha^{2}}+2 Q \ln 10 \frac{\operatorname{Cov}(\alpha, \beta)}{\alpha^{3}}\right]^{2}
\end{aligned}
$$

and

$$
\begin{aligned}
\frac{\left(S D_{\ln A}^{2}\right)^{2}}{\phi_{\ln A}}= & \frac{1}{\phi_{\ln K_{I C}}}\left(4 S D_{\ln K_{I c}}^{2}\right)^{2}+\frac{1}{\phi_{\ln \sigma_{i}}}\left[\frac{(1-3 \alpha)^{2}}{\alpha^{2}} S D_{\ln \sigma_{i}}^{2}\right]^{2} \\
& +\frac{1}{\phi_{\alpha \beta}}\left[\left(Q-\frac{\alpha}{1-3 \alpha}\right)^{2} \frac{S D_{\alpha}^{2}}{\alpha^{4}}+(\ln 10)^{2} \frac{S D_{\beta}^{2}}{\alpha^{2}}\right. \\
& \left.+2 \ln 10\left(Q-\frac{\alpha}{1-3 \alpha}\right) \frac{\operatorname{Cov}(\alpha, \beta)}{\alpha^{3}}\right]^{2}
\end{aligned}
$$

where $\phi_{\sigma_{i}}$ is the DOF in inert strength (number of inert strength tests -1 ) and $\phi_{\alpha \beta}$ is the DOF in regression (number of constant stress rate tests -2 ).

Three approaches were used to estimate the slope and intercept of Eq. (3): linear regression of: (1) the individual data points; (2) the median values; and (3) the average values. In addition to the approaches described, the fits were performed over several stress-rate ranges to determine the sensitivity to inclusion of large stress rates.

\section{Results}

\subsection{Fracture toughness}

Examples of load-backface strain curves for laboratory air and dry N2 are shown in Fig. 1 for the Electro-Glass 2164. Stable fracture was exhibited in both environments; however, less stability was exhibited in dry nitrogen. Fracture toughness of the glasses tested exhibited a narrow range in dry nitrogen (0.67$0.80 \mathrm{MPa} \sqrt{ } \mathrm{m})$, as summarized in Table 1 . The fracture toughness of the glasses is nominally $3 / 4 \mathrm{MPa} \sqrt{ } \mathrm{m}$. Testing in air (30-60\% $\mathrm{RH})$ reduced the measured fracture toughness significantly. The S8070 glass-ceramic exhibited more than twice the fracture toughness of the glasses.

\subsection{Inert and time-dependant strength}

The fracture strength as a function of stress rate is plotted in Figs. 2-5. The large degree of scatter, particularly at low $\mathrm{RH}$, is indicative of the difficulty in characterizing and designing glasses

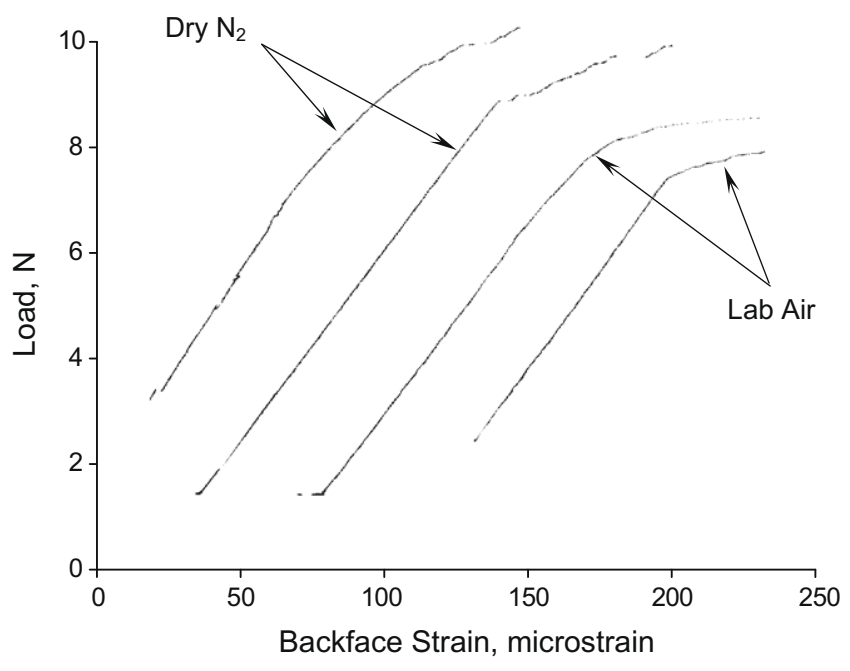

Fig. 1. Load as a function of backface strain for Electro-glass 2164 chevron-notched flexure specimens in dry nitrogen and laboratory air.

Table 1

Fracture toughness $(\mathrm{MPa} \sqrt{ } \mathrm{m})$ of glasses.

\begin{tabular}{lll}
\hline Material & Environment & \\
\hline & Air $\left(\% \mathrm{RH} /{ }^{\circ} \mathrm{F}\right)$ & Dry $_{2}$ \\
0120 & $0.50 \pm 0.02(34 / 76)$ & $0.67 \pm 0.02$ \\
2164 & $0.61 \pm 0.05(32 / 73)$ & $0.74 \pm 0.03$ \\
S8061 & $0.64 \pm 0.01(23 / 73)$ & $0.72 \pm 0.02$ \\
S8070 & $1.57 \pm 0.03(60 / 73)$ & $1.90 \pm 0.03$ \\
8330 & $0.61 \pm 0.04(60 / 73)$ & $0.72 \pm 0.04$ \\
Soda-lime silicate & $0.75 \pm 0.04(35 / 73)$ & $0.80 \pm 0.01$ \\
Ba-doped & $0.72 \pm 0.002(23 / 73)$ & $0.76 \pm 0.01$ \\
\hline
\end{tabular}

and dense optical materials with strength measurements of the inherent flaw population: random and spurious damage make the distribution ever changing and difficult to characterize, regardless of Weibull statistics. In this testing, the effect of scatter on slow crack growth was mitigated partially by the large range of stress rates used ( $>4$ orders of magnitude). All the materials, except the S8070 SB glass-ceramic, exhibit a strength increase from $\sim 50 \mathrm{MPa}$ in $95 \% \mathrm{RH}$ to $\sim 150 \mathrm{MPa}$ in $2 \% \mathrm{RH}$ as the stress rate is increased from $0.001 \mathrm{MPa} / \mathrm{s}$ to $1000 \mathrm{MPa} / \mathrm{s}$, implying a similar combination of flaw size distribution and fracture toughness. As the fracture toughness values are similar (Table 1), the implication is a similar flaw size distribution.

The slow crack growth parameters as estimated from Eqs. (5)(17) are summarized in Table 2.

\section{Discussion}

\subsection{Effects of humidity}

Table 2 demonstrates that lower test humidity systematically results in higher estimates of $n$ and $B$, regardless of the type of glass tested, implying that controlling or eliminating moisture via coatings, etc. will improve component life. The variances are also somewhat larger for dry conditions because the shallower slope is more difficult to characterize for the same stress-rate range. The parameters are also very sensitive to small changes in humidity at low humidity: the value of $B$ changes by a factor of $>100$ for a change of $3 \%$ to $1 \%$ RH whereas a change from $95 \%$ to $3 \% \mathrm{RH}$ results in a factor of $<10$ change. 
0120 95\% RH

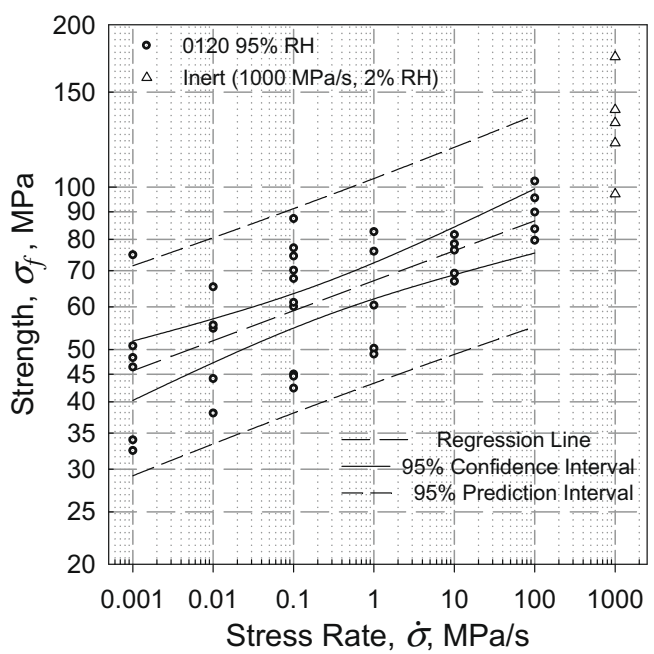

$01202 \% \mathrm{RH}$

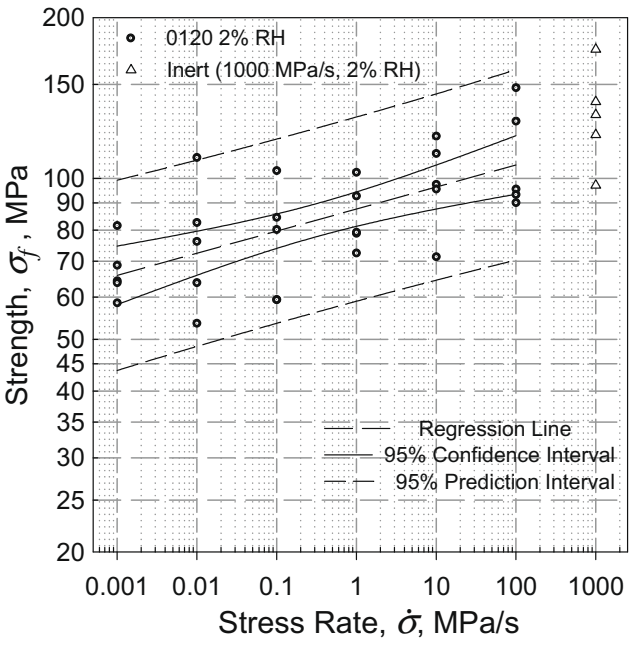

Fig. 2. Strength of 0120 glass in $2 \%$ and $95 \%$ relative humidity.

2164 95\% RH

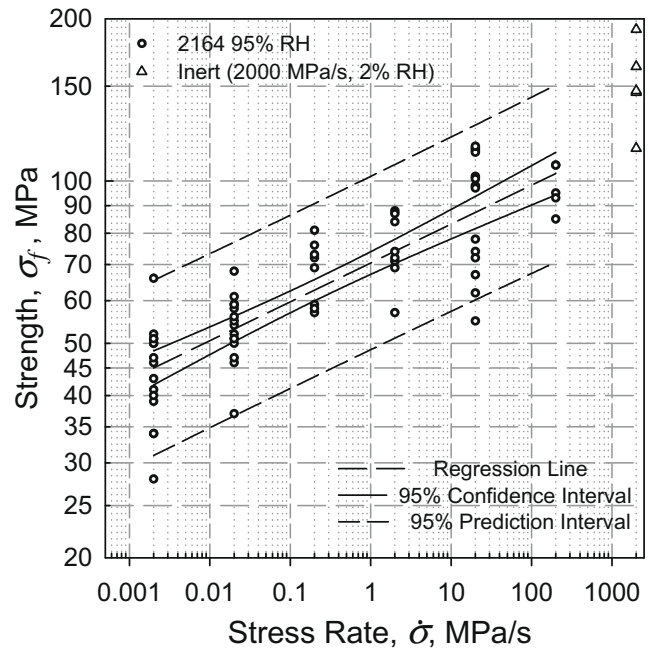

2164 2\% RH

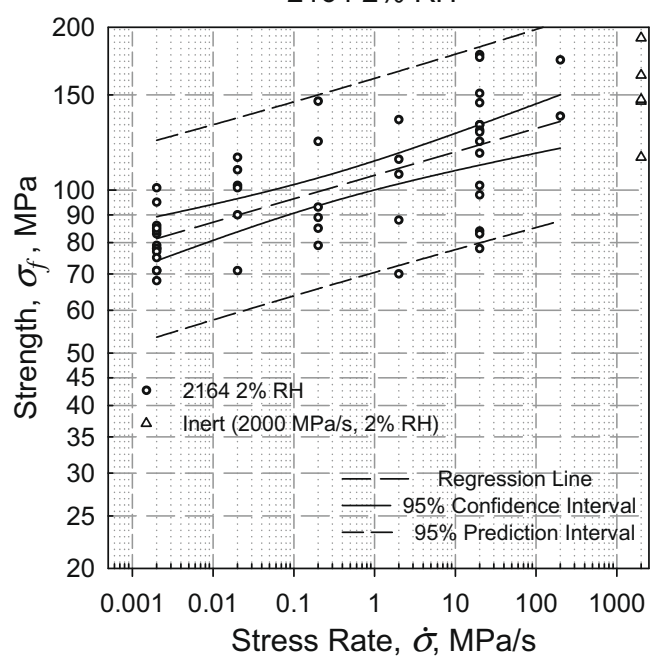

Fig. 3. Strength of 2164 in $2 \%$ and $95 \%$ relative humidity.
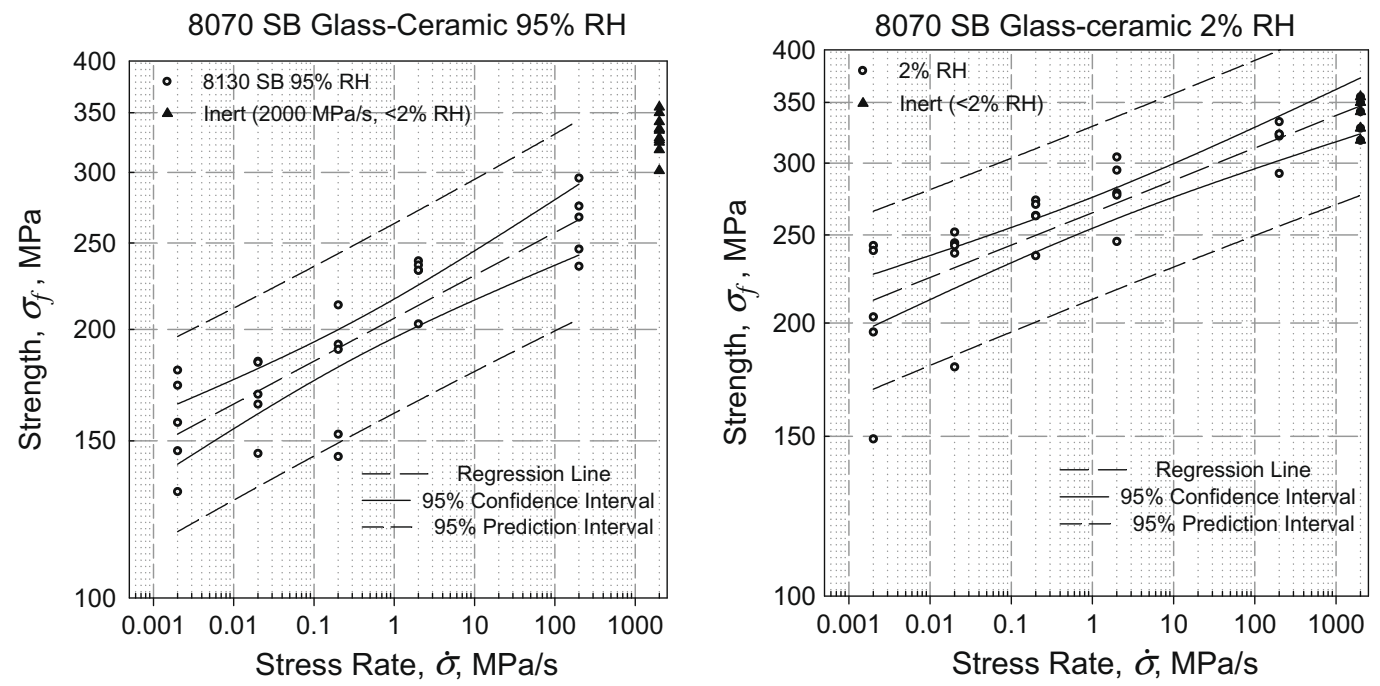

Fig. 4. Strength of S8070 SB glass-ceramic in $2 \%$ and $95 \%$ relative humidity. 
8330 Borofloat 95\% RH

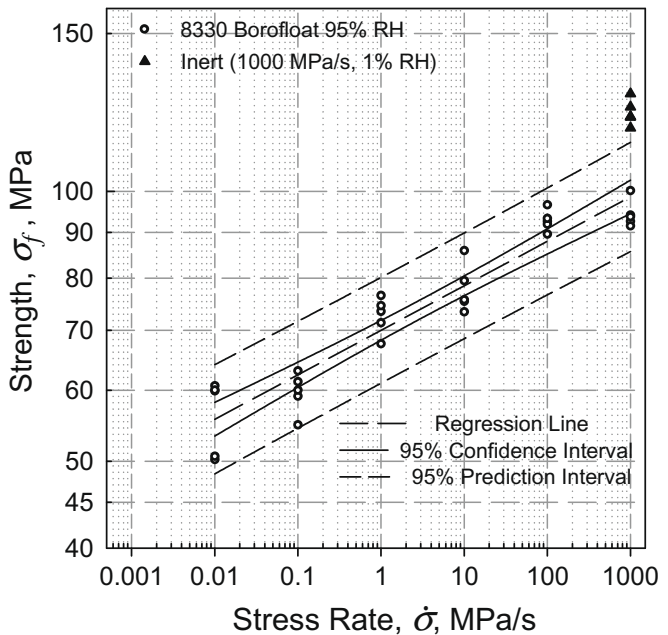

8330 Borofloat $1 \% \mathrm{RH}$

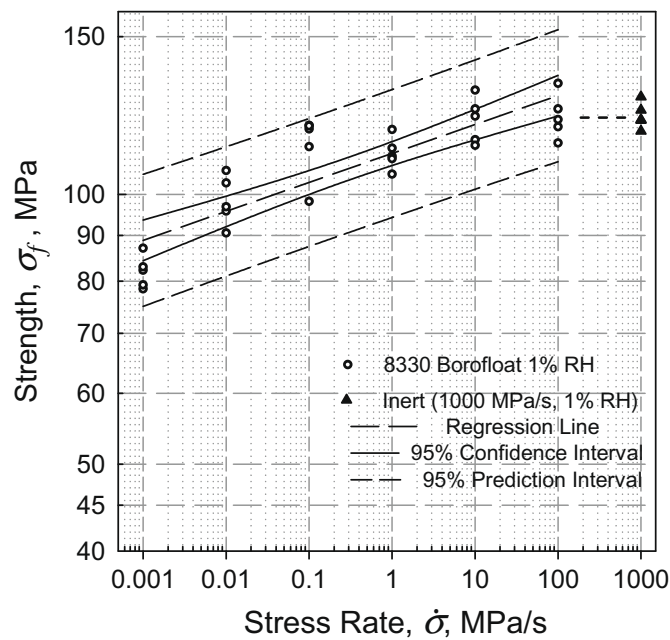

Fig. 5. Strength of 8330 borosilicate glass in $1 \%$ and $95 \%$ relative humidity.

Table 2

Summary of slow crack growth (SCG) parameters for glasses.

\begin{tabular}{|c|c|c|c|c|c|c|}
\hline Regression of individual points & $n$ & $B\left(\mathrm{MPa}^{2} \mathrm{~s}\right)$ & $B_{-95 \%}$ & $A \mathrm{~m} / \mathrm{s}(\mathrm{MPa} \sqrt{ } \mathrm{m})^{-n}$ & $A_{+95 \%}$ & \# Tested \\
\hline $0120,95 \%$ RH & $17.0 \pm 3.1$ & 0.6 & $1.8 \times 10^{-4}$ & $2.4 \times 10^{+1}$ & $3.2 \times 10^{+5}$ & 36 \\
\hline $0120,2 \%$ RH & $23.2 \pm 5.3$ & 4.3 & $1.0 \times 10^{-4}$ & $2.8 \times 10^{+1}$ & $1.2 \times 10^{+7}$ & 30 \\
\hline $2164,95 \% \mathrm{RH}$ & $12.9 \pm 1.1$ & 6 & 06 & $2.3 \times 10^{-1}$ & $3.4 \times 10^{+1}$ & 65 \\
\hline $2164,2 \% \mathrm{RH}$ & $22.1 \pm 3.9$ & 39 & 01 & $3.0 \times 10^{-1}$ & $4.4 \times 10^{+3}$ & 48 \\
\hline S8070, 95\% RH & $19.8 \pm 2.6$ & 60 & 1.6 & $4.9 \times 10^{-9}$ & $3.9 \times 10^{-8}$ & 25 \\
\hline S8070, $2 \%$ RH & $25.0 \pm 3.9$ & 3079 & 93 & $2.6 \times 10^{-12}$ & $1.2 \times 10^{-10}$ & 25 \\
\hline $8330,95 \% \mathrm{RH}$ & $17.1 \pm 1.3$ & 5 & 0.7 & $5.6 \times 10^{-1}$ & $1.0 \times 10^{+1}$ & 25 \\
\hline $8330,3 \%$ RH & $24.5 \pm 3.9$ & 19 & 0.4 & $8.0 \times 10^{-1}$ & $3.1 \times 10^{+2}$ & 30 \\
\hline $8330,1 \% \mathrm{RH}$ & $30.0 \pm 3.6$ & 2855 & 266 & $2.1 \times 10^{-2}$ & $2.3 \times 10^{+0}$ & 30 \\
\hline
\end{tabular}

Table 3

Comparison of fitting ranges and methods for the 8330 borosilicate glass tested in $95 \% \mathrm{RH}$.

\begin{tabular}{|c|c|c|c|c|}
\hline Fit method & $n$ & $B\left(\mathrm{MPa}^{2} \mathrm{~s}\right)$ & $A \mathrm{~m} / \mathrm{s}(\mathrm{MPa} \sqrt{ } \mathrm{m})^{-n}$ & \# Tested \\
\hline \multicolumn{5}{|c|}{ All data (high rate included) } \\
\hline Individual points & $19.2 \pm 1.3$ & 1 & $3.7 \times 10^{0}$ & 30 \\
\hline Median values & $21.6 \pm 3.0$ & 0.4 & $2.1 \times 10^{1}$ & 6 \\
\hline Average values & $19.3 \pm 2.0$ & 1 & $3.9 \times 10^{0}$ & 6 \\
\hline \multicolumn{5}{|c|}{$<1000 \mathrm{MPa} / \mathrm{s}$ (avoid inert region) } \\
\hline Individual points & $17.1 \pm 1.3$ & 5 & $5.6 \times 10^{-1}$ & 25 \\
\hline Median values & $19.9 \pm 3.6$ & 1 & $4.5 \times 10^{0}$ & 5 \\
\hline Average values & $17.2 \pm 1.8$ & 5 & $5.9 \times 10^{-1}$ & 5 \\
\hline
\end{tabular}

\subsection{Effect of fit method and range}

The effects of fit range and method on the estimated parameters can be seen in Tables 3 and 4: the fitting methods produce similar results for a data set; and the inclusion of the high stress-rate data (1000 MPa/s) substantially alters the results at low humidity by increasing the estimated $n$. The lack of an effect of fit method implies either few outliers or sufficient data to mitigate the influence of outliers. The effect of fit range can be mitigated by using crack growth data only from lower stress rates $(<\sim 200 \mathrm{MPa} / \mathrm{s})$ [9], and independently measuring inert strength with $\sim 0 \% \mathrm{RH}$. This avoids combining the different regions of the slow crack curve when estimating parameters.

\subsection{Confidence intervals}

The $95 \%$ confidence intervals on $B$ for the sealing glasses in Table 2 differ from the estimates by $1-3$ orders of magnitude, even for data sets with 60 observations. The relatively large confidence intervals on some of the data sets imply that the use of inherent or natural flaws requires very large data sets. Improvements can also be made by maximizing the range of rates used, and by performing most of tests at the highest and lowest rates. However, as the test range is shifted to slower rates, the test time increases

Table 4

Comparison of fitting ranges and methods for the 8330 borosilicate glass tested in $1 \%$ $\mathrm{RH}$.

\begin{tabular}{llllc}
\hline Fit method & $n$ & $B\left(\mathrm{MPa}^{2} \mathrm{~s}\right)$ & $A \mathrm{~m} / \mathrm{s}(\mathrm{MPa} \sqrt{ } \mathrm{m})^{-n}$ & \# Tested \\
\hline \multicolumn{2}{l}{ All data (high rate included) } & & & \\
Individual points & $36.8 \pm 4.4$ & 608 & $5.5 \times 10^{-1}$ & 35 \\
Median values & $38.2 \pm 11.2$ & 541 & $9.0 \times 10^{-1}$ & 7 \\
Average values & $36.8 \pm 8.8$ & 632 & $5.4 \times 10^{-1}$ & 7 \\
$<1000 \mathrm{MPa} / \mathrm{s}$ (avoid inert region) & & & \\
Individual points & $30.0 \pm 3.6$ & 2855 & $2.1 \times 10^{-2}$ & 30 \\
Median values & $30.4 \pm 8.7$ & 3032 & $2.2 \times 10^{-2}$ & 6 \\
Average values & $30.0 \pm 7.0$ & 2984 & $2.0 \times 10^{-2}$ & 6 \\
\hline
\end{tabular}


substantially. Monte Carlo estimates compared reasonably well with estimates from Eqs. (10)-(17), as shown on Table 5.

\subsection{Crack velocity}

The crack velocity as a function of stress intensity based on the estimated parameters in Table 2 is shown in Figs. 6 and 7. The S8070 glass-ceramic exhibited the least crack velocity whereas the 0120 and 2164 glasses exhibited the greatest velocities at any stress intensity. Application of common time-to-failure equa-

Table 5

Comparison of propagation of errors (Eqs. (10)-(17)) and Monte Carlo estimates.

\begin{tabular}{lcllc}
\hline $\begin{array}{l}\text { Material and } \\
\text { humidity }\end{array}$ & $B\left(\mathrm{MPa}^{2} \mathrm{~s}\right)$ & $\begin{array}{l}B_{-95 \%} \\
\left(\mathrm{MPa}^{2} \mathrm{~s}\right)\end{array}$ & $\begin{array}{l}A \mathrm{~m} / \mathrm{s} \\
(\mathrm{MPa} \sqrt{ } \mathrm{m})^{-n}\end{array}$ & $\begin{array}{l}A_{+95 \%} \mathrm{~m} / \mathrm{s} \\
(\mathrm{MPa} \sqrt{ })^{-n}\end{array}$ \\
\hline 2164, 95\% RH & 5.7 & 0.06 & 0.230 & 34.1 \\
Monte Carlo & 6.1 & 0.11 & 0.217 & 20.2 \\
2164, <2\% RH & 39 & 0.009 & 0.298 & 4361 \\
Monte Carlo & 41 & 0.011 & 0.263 & 12,891 \\
\hline
\end{tabular}

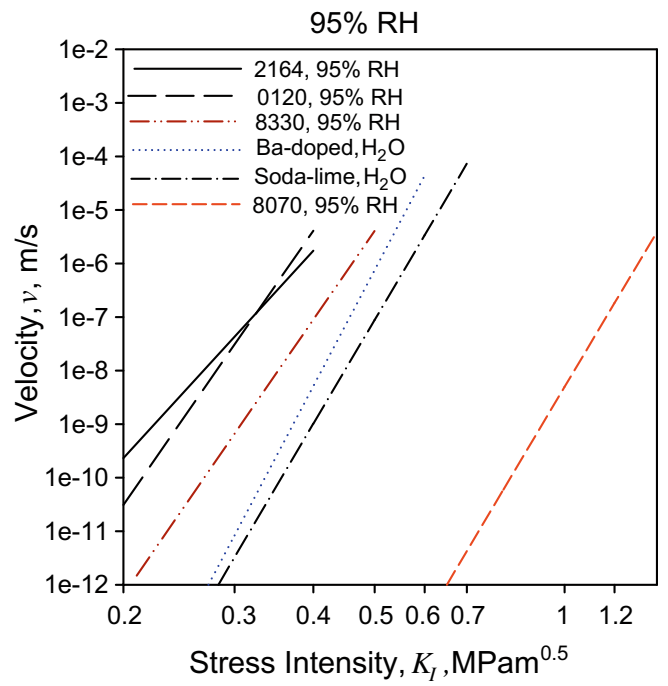

Fig. 6. Crack velocity for $95 \%$ relative humidity based on the parameters in Table 2 .

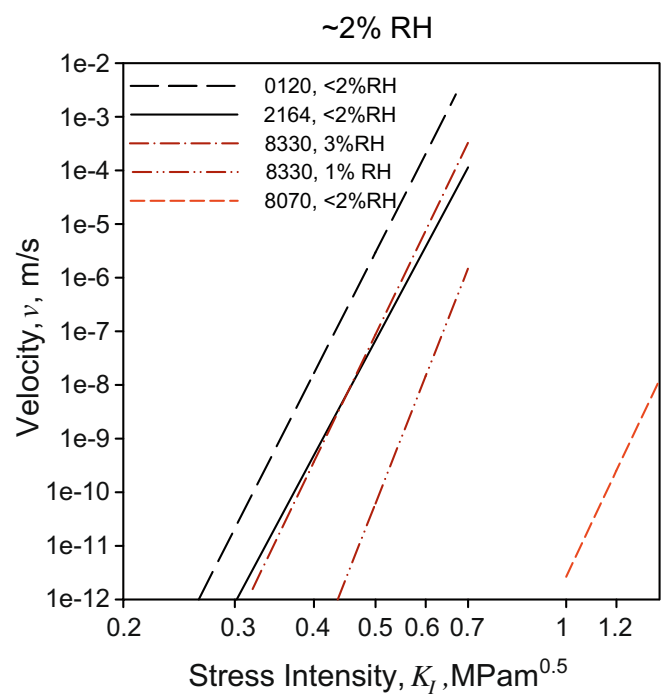

Fig. 7. Crack velocity for $1-3 \%$ relative humidity based on the parameters in Table 2 . tions [7] indicates that the the sustainable stress for the S8070 is doubled if the humidity is changed from $95 \%$ to $2 \%$. As compared to soda-lime silicate float glass, the sealing glasses exhibit greater susceptibility to slow crack growth, as shown in Fig. 6.

\subsection{Reduction of scatter}

Scatter in strength tests is reduced when the initial flaw population is made more uniform. This can be achieved by introducing a precrack, such as that formed when a brittle material is indented or scratched. In order to compare results from various flaw types and determine if scatter could be reliability reduced, a series of Badoped glass specimens were tested after either abrading with $150 \mathrm{~J}$ grit alumina cloth or after precracking with a Vickers indenter at $10 \mathrm{~N}$. Abrasion left long, shallow surface cracks while indentation left deeper semi-elliptical cracks about the indentation. The abraded specimens were subjected to either uniaxial or biaxial flexure testing, while the indented specimens to uniaxial flexure. Environments of $60 \% \mathrm{RH}$ air or distilled water were used. The inert strength was measured in silicone oil, and the fracture toughness was measured by using the chevron-notched beam (see Table 1) and the single-edged-precracked-beam [10], which gave a slightly lower fracture toughness of $0.73 \mathrm{MPa} \sqrt{ } \mathrm{m}$. An example of fracture stress as a function of stress rate for abraded specimens subjected to biaxial flexure is shown in Fig. 8.

Because the precracking process results in residual stress about the crack, the correction factors of Fuller [11] were used to estimate the parameters shown in Table 6:

$n=4 n^{\prime} / 3-2 / 3 \quad$ and $\quad B=B^{\prime}\left[\frac{3^{\left(n^{\prime}-2\right)}}{\left.(n-2)(4)^{(n-3}\right)} \frac{\Gamma(n)}{\Gamma\left(n^{\prime}\right) \Gamma\left(n-n^{\prime}\right)}\right]$

(point flaw)

$n=2 n^{\prime}-2 \quad$ and $\quad B=B^{\prime}\left[\frac{1}{(n-2)(2)^{(n-3)}} \frac{\Gamma(n)}{\Gamma\left(n^{\prime}\right) \Gamma\left(n-n^{\prime}\right)}\right]$

(line flaw)

where $n^{\prime}$ is the uncorrected value calculated by assuming Eq. (5), $n$ is the value corrected for residual stresses, and $\Gamma(z)$ is the gamma function of the argument $z$. The associated standard deviations can be derived from propagation of errors:

$S D_{n}^{\text {point flaw }} \approx \frac{2 S D_{n^{\prime}}}{\sqrt{3}}$

$S D_{n}^{\text {line flaw }} \approx \sqrt{2} S D_{n^{\prime}}$

The most consistent parameter sets result by using the point-flaw correction for the indented specimens and the line-flaw correction for the abraded specimens, and stress intensity factor coefficients for $1 / 2$ penny and long surface cracks, respectively ( $Y=1.28$ for indented and $Y=1.95$ for abraded). This results in relatively similar values of $n=\sim 23$ for abraded and $n=\sim 20$ for indented. Statistical comparison of the slopes ( $\alpha^{\prime}$ s used to calculate $n$ ) by using the $F$ statistic at $95 \%$ confidence indicate the slope estimates to be statistically different. Despite the differences in $n$, the values of $B$ and $A$ for a specific environment are very comparable for engineering purposes, as shown in Table 7.

Parameters $n$ and $B$ generated in water are systematically smaller than those generated in lab air, in agreement with the sealing glass results. Biaxial and uniaxial testing produce very similar results. The effect of the difference in parameters on crack velocity between indented and abraded specimens can be seen in Figs. 9 and 10 . Overall, the velocities in water for the corrected parameters cluster better than those without correction.

Note worthy are the small standard deviations of $n$ produced by indentation despite the small number of tests (15 vs. 115). Also, 

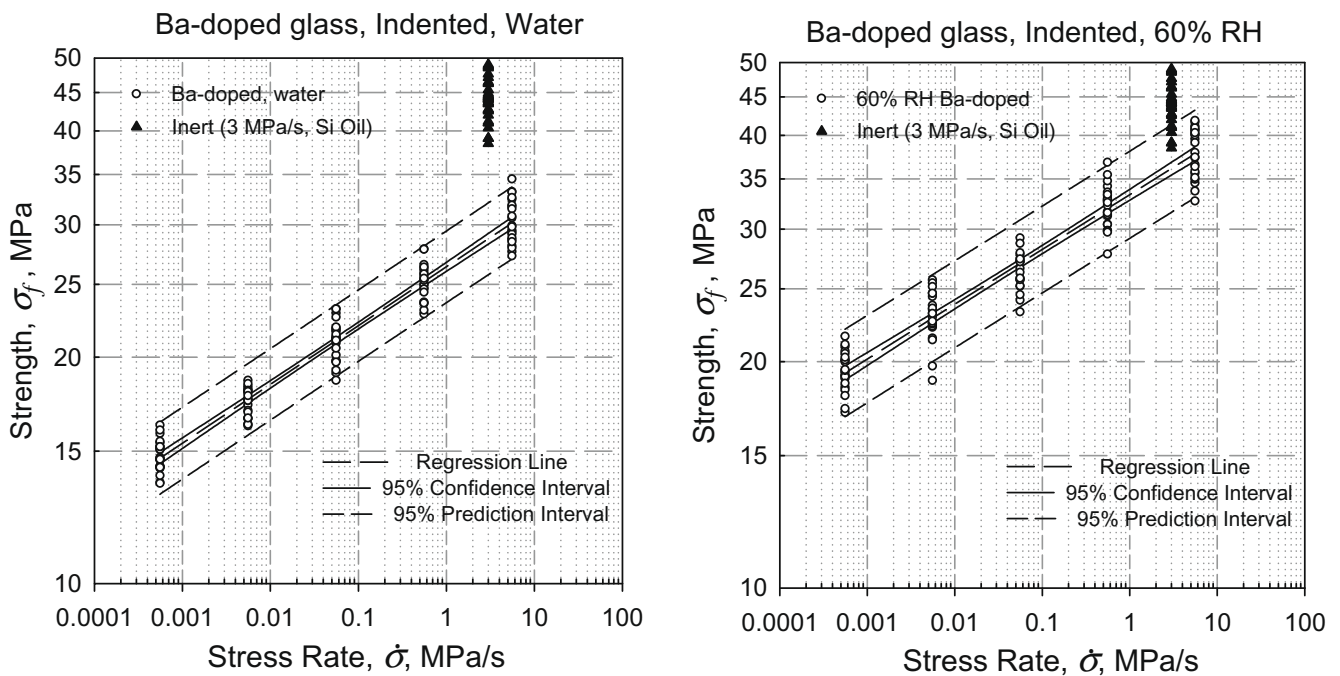

Fig. 8. Strength of Ba-doped glass in $60 \% \mathrm{RH}$ air and distilled water.

Table 6

Comparison of parameters produced from indented and abraded specimens subjected to uniaxial and biaxial flexure.

\begin{tabular}{lrlll}
\hline Test condition & \multicolumn{1}{l}{$n^{\prime}$} & $n$ Point flaw & $n$ Line flaw & \# Tested \\
\hline Abraded & & & & \\
Uniaxial, air & $13.1 \pm 0.4$ & $17 \pm 0.4$ & $24 \pm 0.5$ & 115 \\
Uniaxial, $\mathrm{H}_{2} \mathrm{O}$ & $12.2 \pm 0.4$ & $16 \pm 0.4$ & $22 \pm 0.5$ & 115 \\
Biaxial, air & $12.7 \pm 0.4$ & $16 \pm 0.4$ & $23 \pm 0.5$ & 111 \\
Biaxial, $\mathrm{H}_{2} \mathrm{O}$ & $11.8 \pm 0.3$ & $15 \pm 0.3$ & $22 \pm 0.4$ & 112 \\
Indented, uniaxial & & & & \\
$\mathrm{Air}$ & $15.5 \pm 0.5$ & $20 \pm 0.6$ & $29 \pm 0.7$ & 15 \\
$\mathrm{H}_{2} \mathrm{O}$ & $14.8 \pm 1.0$ & $19 \pm 1.1$ & $28 \pm 1.4$ & 15 \\
$\mathrm{H}_{2} \mathrm{O}$, annealed & $20 \pm 1.1$ & - & - & 25 \\
\hline
\end{tabular}

Table 7

Parameters produced from indented and abraded specimens subjected to uniaxial and biaxial flexure in lab air and water.

\begin{tabular}{llllc}
\hline Test condition & $n$ & $B\left(\mathrm{MPa}^{2} \mathrm{~s}\right)$ & $A \mathrm{~m} / \mathrm{s}(\mathrm{MPa} \sqrt{ } \mathrm{m})^{-n}$ & \# Tested \\
\hline Air & & & & \\
Abraded, uniaxial & $24 \pm 0.5$ & 29 & $8.6 \times 10^{-1}$ & 115 \\
Abraded, biaxial & $23 \pm 0.5$ & 37 & $5.7 \times 10^{-1}$ & 111 \\
Indented, uniaxial & $20 \pm 0.6$ & 27 & $7.4 \times 10^{-1}$ & 15 \\
Water & & & & \\
Abraded, uniaxial & $22 \pm 0.5$ & 4.0 & $3.9 \times 10^{-0}$ & 115 \\
Abraded, biaxial & $22 \pm 0.4$ & 2.7 & $4.7 \times 10^{-0}$ & 112 \\
Indented, uniaxial & $19 \pm 1.1$ & 3.7 & $2.1 \times 10^{-0}$ & 15 \\
Indented, annealed & $20 \pm 1.1$ & 8 & $1.1 \times 10^{-0}$ & 25 \\
\hline
\end{tabular}

they are less than $1 / 4$ of those for the sealing glasses. Probability limits on the parameter $B^{\prime}$ were estimated using Eqs. (10)-(16) and are given in Table 8. For the abraded specimens, about one order of magnitude exists between the estimated $B$, which is proportional to the time-to-failure, and $B_{-95 \%}$. For the indented specimens, the difference is about $\sim 1.5$ orders, implying that a relatively small set of indented specimens can be used to reasonably estimate $B$.

The small but significant differences between $n$ values from indentation and abrasion could be due to the abrasive not producing the residual stress field represented by the line-flaw correction. This was investigated by testing specimens that were annealed at $520{ }^{\circ} \mathrm{C}$ for $2 \mathrm{~h}$ after indentation. This removes the preexisting residual stresses associated with the indentation, and thereby

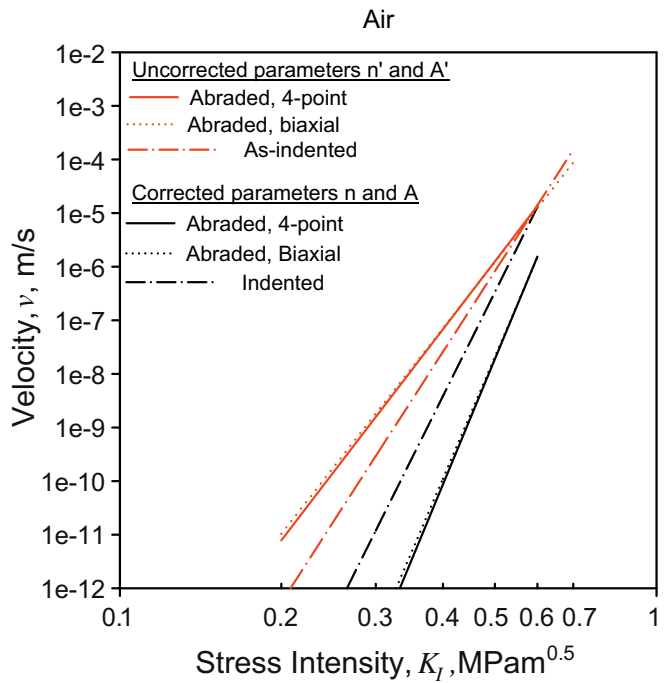

Fig. 9. Crack velocity of abraded and indented Ba-doped glass subjected to uniaxial and biaxial flexure in air.

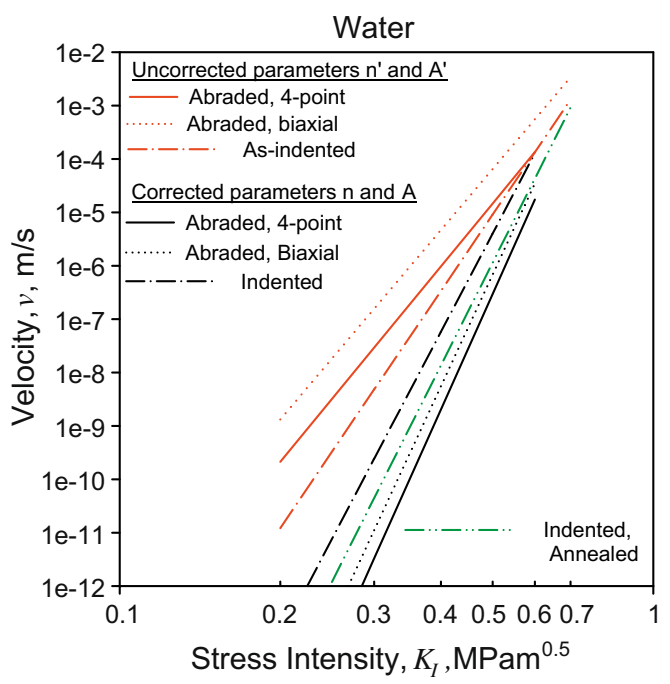

Fig. 10. Crack velocity of abraded and indented Ba-doped glass subjected to uniaxial and biaxial flexure in water. 
eliminates the need for correction via Eq. (20). As shown in Table 7 and Fig. 10, good agreement is shown between the as-indented test data and annealed data, with less than an order of magnitude difference at any stress intensity. Similar results were found when soda-lime silicate was tested in as-indented and annealed conditions, as shown in Table 9. It should be noted that for the annealed test specimens, the strength at the largest stress rate is greater and more scattered than expected as shown in Fig. 11, implying that annealing blunts the crack tip. Evidently some time under load is required for a sharp crack to develop from the annealed crack, and thus excessive stress rate must again be avoided. The higher $n$ values from Eq. (21) imply that either the abraded specimens did not ideally represent line flaws or that Eq. (21) slightly overestimates the necessary correction.

It should be noted that glass components may contain flaws with associated residual stresses, and the best parameters for design will depend on the exact circumstances. The most conservative approach is to use uncorrected parameters.

\section{Table 8}

Probability limits on crack growth parameter $B^{\prime}$ estimated from abraded and indented test specimens.

\begin{tabular}{lrrr}
\hline Test condition & $B_{\text {upper }}^{\prime} 95 \%$ & $B^{\prime}$ & $B_{\text {lower } 95 \%}^{\prime}$ \\
\hline Air & & & \\
Abraded, uniaxial & 921 & 92 & 9 \\
Abraded, biaxial & 883 & 113 & 15 \\
Indented, uniaxial & 1425 & 96 & 6 \\
Water & & & \\
Abraded, uniaxial & 102 & 12 & 1 \\
Abraded, biaxial & 53 & 8 & 1 \\
Indented, uniaxial & 229 & 13 & 1 \\
Indented, annealed & 62 & 14 & 3 \\
\hline
\end{tabular}

Table 9

Summary of slow crack growth parameters of soda-lime silicate in distilled water.

\begin{tabular}{lllll}
\hline Test condition & $n$ & $B \mathrm{MPa}^{2} \mathrm{~s}$ & $A \mathrm{~m} / \mathrm{s}(\mathrm{MPa} \sqrt{ } \mathrm{m})^{-n}$ & $\#$ Tested \\
\hline $\begin{array}{c}\text { Indented, corrected } \\
\text { w/Eq. (20) }\end{array}$ & $20.1 \pm 0.9$ & 5 & $7.5 \times 10^{-1}$ & 20 \\
$\begin{array}{l}\text { Indented then annealed } \\
20.0 \pm 2.0\end{array}$ & 18 & $2.1 \times 10^{-1}$ & 30 \\
\hline
\end{tabular}

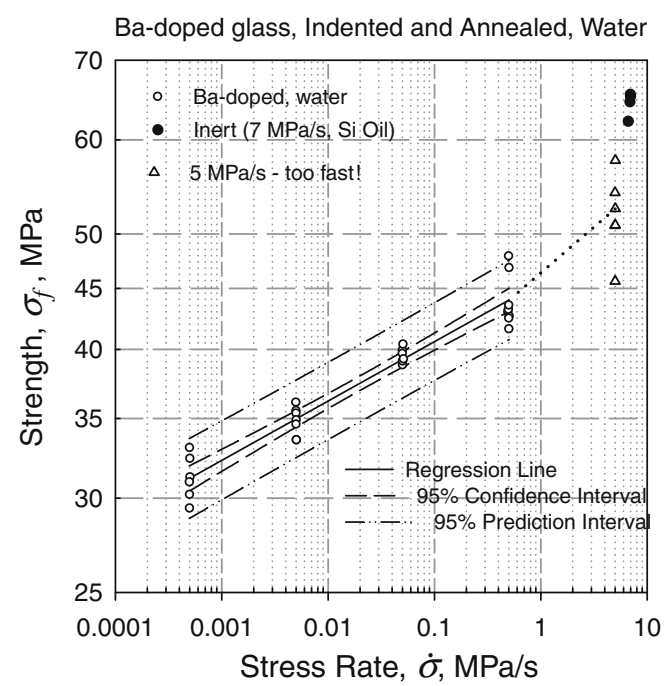

Fig. 11. Strength of Ba-doped glass as a function of stress rate distilled water after indentation and annealing.

\section{Conclusions}

SCG parameters measured using constant stress rate testing in high humidity are systematically smaller ( $n$ and $B$ ) than those measured in low humidity. Velocities for dry environments are $\sim 100 \times$ lower than for wet environments: keeping components dry should significantly extend the life. The crack velocity is very sensitive to small changes in $\mathrm{RH}$ at low $\mathrm{RH}$ : for the 8330 glass, a $\sim 100 \times$ change in velocity results for an $\mathrm{RH}$ change of $1 \%$ to $3 \%$ and for $3-95 \%$. S8070 SB glass-ceramic exhibits the lowest crack velocities of the sealing glasses tested, and reducing $\mathrm{RH}$ from $95 \%$ to $2 \%$ nearly doubles the sustainable stress.

The use of high stress-rate data increased estimates of $n$ at low RH: parameter fits to high stress-rate data (e.g. >100 MPa/ s) should be made with caution, especially for annealed material. Annealing of indentation cracks produce very similar parameters as as-indented specimens when a correction factor was applied. Indentation and abrasion flaws resulted in statistically similar values of $B$ and $A$, however, estimates of $n$ were significantly different by $\sim 15 \%$ after correction for residual stresses. Biaxial and uniaxial stress states produced very similar crack growth parameters.

Monte Carlo simulations and propagation of errors solutions gave similar estimates of parameter variance. Future work should include measurement of the parameters with macro-crack test specimens for comparison.

\section{Acknowledgements}

The authors thank J. Jill Glass of Sandia National Laboratories for many useful discussions, and Frank Kody and Sara Caruso of the NASA Summer Intern Program for running the soda-lime silicate SCG tests.

\section{References}

[1] NASGRO. Fracture mechanics and fatigue crack growth analysis software, version 5.1. San Antonio (TX): Southwest Research Institute.

[2] Salem JA. Mechanical characterization of ZnSe windows for use with the flow enclosure accommodating novel investigations in combustion of solids (FEANICS) Module, NASA TM 214100; 2006.

[3] ASTM C 1161. Standard test method for flexural strength of advanced ceramics at ambient temperature. In: Annual book of standards, vol. 15.01. West Conshohocken (PA): American Society for Testing and Materials; 2004.

[4] ASTM C 1259. Standard test method for dynamic Young's Modulus, Shear Modulus, and Poisson's ratio for advanced ceramics by impulse excitation of vibration. In: Annual book of standards, vol. 15.01. West Conshohocken (PA): American Society for Testing and Materials; 2004.

[5] ASTM C 1421-99. Standard test method for the determination of fracture toughness of advanced ceramics at ambient temperatures. In: Annual book of ASTM standards, vol. 15.01. West Conshohocken (PA): American Society for Testing and Materials; 2000.

[6] Salem JA, Ghosn LJ. Back-face strain as a method for monitoring stable crack extension in ceramics. Ceram Eng Sci Proc 1998;19(3):587-94.

[7] Ritter JE. Engineering design and fatigue failure of brittle materials. in: Fracture mechanics of ceramics, vol. 4. In: Bradt RC, Hasselman DPH, Lange FF, editors, Plenum Publishing Co., (NY); 1978. p. 661-86.

[8] Salem JA, Weaver AS. Estimation and simulation of slow crack growth parameters from constant stress rate data. In: Bradt RC, Munz D, Sakai M, White K, editors. Fracture mechanics of ceramics: active materials, nanoscale materials, composites, glass, and fundamentals. Springer; 2005. p. 579-96.

[9] Salem JA, Jenkins MG. The effect of stress rate on slow crack growth parameters. In: Salem JA, Quinn GD, Jenkins MG, editors. Fracture resistance testing of monolithic and composite brittle materials, ASTM STP 1409U. West Conshohocken (PA): American Society for Testing and Materials; January 2002. p. 213-27.

[10] ASTM C 1421-99. Standard test method for fracture toughness of advanced ceramics. In: American society for testing materials annual book of standards, vol. 15.01. West Conshohocken (PA): ASTM; 2002.

[11] Fuller Jr ER, Lawn BR, Cook RF. Theory of fatigue for brittle flaws originating from residual stress concentrations. J Am Ceram Soc 1983;66(5):314-21. 